\title{
Sofrimento social entre trabalhadores do amianto e o ocultamento da ocorrência de doenças asbesto- relacionadas na cidade de Minaçu (GO)
}

Social suffering among asbestos workers and the concealment of asbestosrelated diseases in the city of Minaçu (Brazil)

\section{Arthur Pires Amaral}

\section{(2) OpenEdition Journals}

\section{Edição electrónica}

URL: https://journals.openedition.org/aa/4980

DOI: $10.4000 /$ aa. 4980

ISSN: 2357-738X

\section{Editora}

Programa de Pós-Graduação em Antropologia Social (UnB)

\section{Edição impressa}

Paginação: 249-268

ISSN: 0102-4302

\section{Refêrencia eletrónica}

Arthur Pires Amaral, «Sofrimento social entre trabalhadores do amianto e o ocultamento da ocorrência de doenças asbesto-relacionadas na cidade de Minaçu (GO)», Anuário Antropológico [Online], v.45 n.1 | 2020, posto online no dia 27 janeiro 2020, consultado o 24 julho 2022. URL: http:// journals.openedition.org/aa/4980 ; DOI: https://doi.org/10.4000/aa.4980

\section{(c) (i) (9) $९$}

Creative Commons - Atribuição-NãoComercial-SemDerivações 4.0 Internacional - CC BY-NC-ND 4.0 https://creativecommons.org/licenses/by-nc-nd/4.0/ 


\title{
Sofrimento social entre trabalhadores do amianto e o ocultamento da ocorrência de doenças asbesto-relacionadas na cidade de Minaçu (GO)
}

\author{
Social suffering among asbestos workers and the concealment of \\ asbestos-related diseases in the city of Minaçu (Brazil) \\ DOI: https://doi.org/10.4000/aa.4980
}

\begin{abstract}
Arthur Pires Amaral • Pesquisador independente
Doutor (2019) e Mestre (2012) em Antropologia Social pela Universidade Federal de Goiás. Graduado em Ciências Sociais (2009) pela mesma instituição. Foi professor substituto de Antropologia e Sociologia da Faculdade de Ciências Sociais/UFG. É autor do livro Os riscos do lugar e os lugares do risco, publicado pela Editora Appris em 2015.
\end{abstract}

Tomando o conceito antropológico de sofrimento social como eixo central da discussão, este artigo tem como objetivos descrever e analisar determinados fatores sociais, econômicos, médico-científi$\cos$, morais e institucionais que possibilitaram o ocultamento e a negação da ocorrência de doenças do amianto entre antigos funcionários da empresa mineradora S.A. Minerações Associadas (SAMA), no município goiano de Minaçu. As doenças que levaram muitos desses trabalhadores à morte precoce nunca foram associadas - pela Junta Médica da empresa, bem como por médicos de clínicas e hospitais de Minaçu e de Goiânia (GO) - à exposição ocupacional pregressa às fibras do amianto crisotila, seja na mina de Cana Brava ou nas usinas da SAMA. O ocultamento nesses casos é, também, resultado dos vínculos "maternos" e "maternais" estabelecidos pela mineradora com parcela significativa da população local, há mais de cinco décadas, os quais produzem todo um contexto de vigilância mútua e de retaliações efetivas sobre e entre os moradores da cidade, de maneira a impedir qualquer tipo de acusação pública contra a SAMA.

Amianto. Doenças asbesto-relacionadas (DARs). Sofrimento social. Minaçu. Mineradora SAMA.
Taking the anthropological concept of social suffering as the discussion's central axis, this paper aims to describe and analyze certain social, economic, medical-scientific, moral, and institutional factors that enabled the concealment and denial of asbestos related-diseases among former SAMA mining company employees, in the Brazilian city of Minaçu. The diseases that led many of these workers to early death were never associated - by the company Medical Border, as well as by medical doctors from clinics and hospitals in Minaçu and Goiânia (Brazil) - to previous occupational exposure to chrysotile asbestos fibers, either in the Cana Brava mine or at SAMA mills. The concealment in these cases is also the result of the "maternal" ties established by the mining company with a significant portion of the local population, for over five decades, which produce a whole context of mutual surveillance and effective retaliation over and among the Minaçu city dwellers to prevent any public complaints against SAMA.

Asbestos. Asbestos-related diseases (ARDs). Social suffering. Minaçu, SAMA mining company. 


\section{Introdução}

Este artigo $^{1}$ tem como objetivo discutir os principais processos sociais de adoecimento, sofrimento e morte de ex-funcionários da empresa mineradora S.A. Minerações Associadas (SAMA), no município goiano de Minaçu², em decorrência da exposição ocupacional às fibras do amianto crisotila ${ }^{3}$. Para tanto, tomo como eixo central de minha discussão o conceito antropológico de sofrimento social que, de acordo com Kleinman, Das e Lock (1997, p. ix),

\section{[...] traz para o mesmo espaço um conjunto de problemas humanos que} têm suas origens e consequências nos danos devastadores que a força social pode infligir sobre a experiência humana. 0 sofrimento social resulta do que o poder político, econômico e institucional faz às pessoas e, reciprocamente, de como essas mesmas formas de poder influenciam as respostas aos problemas sociais. [...] Por exemplo, [...] a pobreza é o principal fator de risco para problemas de saúde e morte; no entanto, essa é apenas outra maneira de dizer que a saúde é um indicador social e, de fato, um processo social (Tradução livre) .

Amparado nesta definição, ao longo do texto descrevo determinados fatores sociais, econômicos, morais, médico-científicos e institucionais que possibilitaram a emergência e a manutenção das chamadas doenças asbesto-relacionadas ou, de forma abreviada, DARs - em Minaçu. Entre as DARs se destacam as que atingem os pulmões e/ou a pleura (fina membrana que recobre os pulmões): a asbestose, as placas pleurais, o câncer de pulmão e o mesotelioma de pleura. Estudos epidemiológicos internacionais demonstram, também, que a contaminação pelo amianto pode provocar diferentes tipos de tumores malignos em variadas partes do organismo humano como laringe, estômago, fígado, intestinos, pâncreas, vesícula biliar, peritônio (membrana que recobre a cavidade abdominal) rins, ovários, entre outras (cf. Hammond; Selikoff; Seidman, 1979; Conforti et al., 1981; Landrigan et al., 1999).

Aqueles fatores, por sua vez, produzem diferentes experiências de sofrimento (inter)subjetivo vividas, sobretudo, nos âmbitos doméstico, familiar e hospitalar por ex-funcionários da SAMA que adoeceram gravemente após o trabalho com as fibras do crisotila na área industrial da mineradora. Veremos mais à frente, através da descrição de um caso concreto, que esses trabalhadores vieram a óbito sem terem suas doenças, dores físicas e outros sintomas clínicos, bem como suas aflições, reconhecidos por médicos ligados aos interesses da mineradora SAMA. Daí porque eles, mas também suas viúvas e seus filhos, se identifica(va)m como os revoltados. Tal categoria local remete, diretamente, à condição de desamparo médico-assistencial e financeiro que a empresa os deixou.

A esse grupo social se contrapõe parcela significativa dos moradores de Minaçu, que defende de modo veemente a forte presença da SAMA no município. Além dos próprios administradores e demais funcionários (CLT e terceirizados) da mineradora, também compõem o grupo pró-amianto: os integrantes do Sindicato
1 Resultado de pesquisa de doutorado realizada no Programa de Pós-Graduação em Antropologia Social, da Universidade Federal de Goiás (PPGAS/UFG), com o apoio da Coordenação de Aperfeiçoamento de Pessoal de Nível Superior (CAPES). Agradeço à Prof. ${ }^{a}$ Dr. ${ }^{a}$ Mônica Thereza Soares Pechincha (PPGAS/FCS/ UFG) pela orientação atenta e crítica ao longo de toda a minha pesquisa. Minha tese de doutorado está disponível no Banco Digital de Teses e Dissertações da UFG, e pode ser acessada através do link: https://repositorio.bc.ufg.br/ tede/handle/tede/9686.

2 Localizado no extremo-norte do Estado de Goiás a, aproximadamente, 500 km da capital Goiânia.

3 As rochas amiantíferas se dividem em dois grupos: as serpentinas e os anfibólios. As serpentinas têm como principal variedade a crisotila - também conhecida como "amianto branco". Entre os anfibólios destacam-se as variedades comerciais: crocidolita (amianto azul) e amosita (ou amianto marrom). Muito utilizados na Itália, França, Inglaterra e África do Sul até os anos 1970, hoje em dia os anfibólios estão em desuso. Todo o amianto explorado na mina de Cana Brava, em Minaçu, é da variedade crisotila. 4 Excerto no original em inglês: "[...] brings into a single space an assemblage of human problems that have their origins and consequences in the devastating injuries that social force can inflict on human experience. Social suffering results from what political, economic, and institutional power does to people and, reciprocally, from how these forms of power themselves influence responses to social problems. [...] For example, [...] poverty is the major risk factor for ill health and death; yet this is only another way of saying that health is a social indicator and indeed a social process". 
dos Trabalhadores na Indústria de Extração de Minerais não Metálicos de Minaçu/ GO e Região (STIEBEMGOR), empresários, trabalhadores do comércio varejista, servidores públicos e autoridades políticas ou jurídicas locais, assim como antigos funcionários da SAMA cujas DARs foram, excepcionalmente, diagnosticadas por sua Junta Médica ${ }^{5}$ e que, a partir da assinatura de um acordo extrajudicial com a empresa, receberam dela indenizações em dinheiro e/ou planos de saúde (gratuitos e vitalícios) como medidas reparatórias aos danos corporais causados pelo trabalho com o asbesto crisotila.

Quanto aos aspectos ético-metodológicos referentes à pesquisa etnográfica que subsidiou os resultados apresentados neste artigo, é preciso dizer que o trabalho de campo no município de Minaçu (GO) durou cerca de 10 meses, entre o início de setembro de 2016 e o final de junho de 2017. Antes de estabelecer residência temporária na cidade, elaborei um roteiro de entrevistas semiestruturado e embasado na bibliografia de minha pesquisa (cf. Amaral, 2019), que contemplava os seguintes tópicos para discussão com possíveis interlocutores de Minaçu: i) trajetórias de vida e ocupacional; ii) o trabalho na mineradora SAMA; iii) doenças asbesto-relacionadas e exames médicos; iv) acordos extrajudiciais firmados entre a SAMA e seus funcionários; v) percepções de risco; vi) percepção sobre a empresa mineradora de amianto crisotila e os processos sociais de adoecimento; vii) mobilizações políticas dos trabalhadores expostos às fibras de amianto em Minaçu.

A partir de diálogos iniciais com alguns moradores de Minaçu sobre a existência de trabalhadores possivelmente adoecidos por causa da contaminação ao amianto, foi possível estabelecer novos contatos com pessoas vinculadas às suas redes sociais locais até, finalmente, conseguir identificar familiares de antigos funcionários da SAMA que já haviam falecido em decorrência do agravamento dos sintomas mais latentes de suas doenças - como insuficiência respiratória aguda, cansaço físico extenuante e fortes dores ("pontadas”, "ferroadas”) nas regiões do peito e das costas. Como será discutido ao longo do texto, essas interações sociais foram marcadas por tensões e pela busca de consentimento informado para a realização de entrevistas gravadas entre o pesquisador e seus interlocutores. Isto nos leva, imediatamente, a considerar o universo específico das pesquisas sobre saúde e doença na Antropologia, cujos procedimentos ético-metodológicos se diferem bastante daqueles utilizados, por exemplo, em pesquisas epidemiológicas e biomédicas (cf. Langdon; Maluf; Tornquist, 2008; Duarte, 2004).

Considerando o contexto minaçuense de vigilância mútua e de retaliações efetivas (ameaças e assédios morais, como veremos adiante) por parte da instituição SAMA e de seus funcionários, mas também por grande parte da população de Minaçu, em relação às poucas vozes dissonantes que tentam denunciar os altos riscos à saúde humana da exposição ao asbesto crisotila, é de se esperar que os consentimentos voluntários e individuais que autorizaram a concessão de entrevistas gravadas, bem como o acesso direto a certos documentos (como exames e laudos médicos, além de certidões de óbito) se deu por meio de uma relação não formal de confiança, respeito e confidencialidade construída entre o pesquisador e os sujeitos de interlocução, ao longo de todos os dez meses de trabalho de campo em Minaçu.
5 De acordo com matéria publicada pela Folha de S. Paulo em 12/07/2009: "A SAMA diz monitorar a saúde de cerca de $11 \mathrm{mil}$ trabalhadores e ex-trabalhadores anualmente. Entre todos, ela reconhece aproximadamente cem doentes. O número é considerado subestimado pela ABREA (Associação Brasileira dos Expostos ao Amianto) e por trabalhadores que discordam dos laudos da SAMA". Disponível em: http://feeds.folha.uol.com. br/fsp/dinheiro/ fi1207200917. htm. Acesso em: 21 fev. 2019. 
Em outras palavras, o uso formalizado e pré-determinado do Termo de Consentimento Livre e Esclarecido (TCLE), no qual o interlocutor - com pouca ou nenhuma escolaridade e de baixa renda, em geral - precisava se identificar (declarando nome, RG e CPF) se revelou, no cotidiano de minha pesquisa etnográfica, como um verdadeiro entrave à verbalização de diferentes acusações de violação aos direitos humanos tanto de ex-funcionários da SAMA adoecidos de modo letal pelo amianto, cujas DARs foram ocultadas por médicos de Minaçu e de Goiânia (GO), quanto de suas viúvas e filhos.

\section{Uma etnografia sobre o adoecimento ocupacional pelo amianto, em Mina- çu, a partir de dois contextos internacionais}

Dois trabalhos de cunho histórico-etnográfico, o primeiro escrito pelo cientista social e historiador Jock McCulloch (2002) e o segundo pela antropóloga Linda Waldman (2011), são fundamentais à problematização dos riscos do trabalho com o amianto, das experiências de adoecimento decorrente da exposição às fibras desse mineral, e dos conflitos de interesse que emergem a partir do conluio entre governos regionais, empresas multinacionais e uma ciência médica a serviço dos ganhos financeiros privados da indústria do amianto em países como África do Sul, Inglaterra e Índia.

Resumidamente, estes três casos internacionais introduzem uma discussão mais ampla sobre: i) os processos produtivos implementados pela indústria do amianto em suas minas e usinas; ii) as relações de trabalho presentes no ambiente ocupacional de mineradoras e fábricas que trabalham no processamento das fibras de asbesto; iii) os diferentes contextos socioeconômicos de cidades e outras regiões urbanas construídas próximas às minas e usinas de amianto, bem como às fábricas que produzem materiais à base das fibras desse mineral; iv) as doenças asbesto-relacionadas; v) pesquisas epidemiológicas acerca dos riscos da exposição ao amianto; vi) disputas médicas e jurídicas envolvidas no (não)reconhecimento de trabalhadores com DARs e nas (não)concessões de medidas indenizatórias a eles.

De forma muito semelhante ao contexto sul-africano (cf. McCulloch, 2002), durante o meu trabalho de campo em Minaçu, muitos dos interlocutores locais narraram que, até o final dos anos 1980, havia uma forte concentração da poeira branco-acinzentada do amianto crisotila tanto nos espaços internos da mineradora quanto no restante de todo o município - dando a impressão de que ali "nevava amianto". A tal ponto que essa poeira se depositava dia e noite, ininterruptamente, sobre os corpos dos funcionários da SAMA, mas também sobre ruas, calçadas, residências, quintais, árvores (muitas vezes com frutos comestíveis) e mesmo escolas, fazendo com que crianças, jovens e adultos convivessem, sem outra alternativa, em um ambiente altamente tóxico. Além disso, foi possível constatar que, durante décadas, os trabalhadores tanto das companhias mineradoras de amianto daquele país africano quanto da SAMA, em Minaçu, realizaram o ensacamento manual das fibras já processadas ${ }^{6}$, atividade esta responsável pela maior exposição ocupacional ao asbesto. Lá como cá havia a demissão periódica dos funcionários que apresentassem sinais e sintomas médicos de suas DARs já em estágio avan-
6 Há uma diferença quanto ao tipo de amianto explorado e processado nestes dois contex- 
çado, seguida da contratação de trabalhadores de outras regiões, que ainda não tinham sido contaminados pelo amianto.

Alguns pesquisadores denominam essa estratégia empresarial através da expressão healthy worker effect: as dispensas rotineiras de trabalhadores diagnosticados de forma velada com DARs, bem como a sua imediata substituição, faziam com que as companhias mineradoras mascarassem os dados oficiais sobre a incidência e a prevalência destes problemas de saúde coletiva no interior de minas, usinas e fábricas que manipulavam as fibras de amianto (cf. Waldman, 2011; McCulloch, 2002).

No caso inglês, encontrei uma discussão acerca do comprometimento pessoal, profissional e moral de funcionários com as fábricas que produziam diferentes materiais compostos com asbesto. Ao oferecerem atividades culturais e recreativas, para além do espaço laboral, e garantirem assistências sociais variadas, essas fábricas/empresas conseguiam ligar afetivamente o trabalhador do amianto aos seus empregadores - criando assim uma family ideology (Waldman, 2011). Tal ideologia está bastante presente não apenas no cotidiano dos funcionários da mineradora SAMA, mas também na vida social minaçuense. Este fato dificultou bastante a minha abordagem aos trabalhadores com DARs, e/ou a seus familiares, durante a realização da pesquisa de campo em Minaçu. A negação das dores físicas e dos sofrimentos subjetivo e social se deu, em ambos os contextos, por parte de médicos e outros profissionais de saúde a serviço da indústria do amianto, bem como por parte de cientistas e do sistema judiciário de cada país. Daí ter sido possível observar, tanto na Inglaterra como no Brasil, que as empresas do setor se valeram de acordos extrajudiciais com os ex-funcionários diagnosticados com alguma doença asbesto-relacionada, em uma tentativa de: primeiro, evitar o pagamento de indenizações e multas milionárias em decorrência de ações coletivas impetradas através da justiça comum; e, segundo, obscurecer as possíveis evidências de uma epidemia de DARs (cf. Amaral, 2019).

A experiência indiana com o crisotila (cf. Waldman, 2011) é, a meu ver, aquela que mais se aproxima da realidade dos trabalhadores da SAMA em Minaçu. Assim como na Índia, há também no Brasil um conluio intencional envolvendo a indústria do amianto e certa parcela da comunidade médico-científica. Os seus propósitos vão desde a refutação do alto potencial carcinogênico do asbesto crisotila à saúde humana até a manipulação dos resultados de exames clínicos e médicos, realizados por trabalhadores com DARs a pedido das próprias companhias daquele setor mineral. Todo este processo de negar os possíveis riscos da exposição às fibras respiráveis do crisotila e de enganar os trabalhadores, bem como o restante da sociedade, quanto à letalidade dessa variedade comercial do amianto, é fundamentado por meio de estudos epidemiológicos financiados, em grande medida, por companhias mineradoras de asbesto (como a SAMA) e por fábricas produtoras de materiais à base de fibrocimento-amianto. Tais pesquisas, com aparência de idoneidade, são responsáveis pela elaboração de uma narrativa industrial hegemônica sobre o crisotila, que lhe atribui uma menor toxicidade quando comparado às variedades crocidolita e amosita, sobretudo em condições tos. Nas cidades sul-africanas, a principal variedade de amianto existente era a crocidolita, embora também houvesse uma grande produção de fibras de amosita. Por sua vez, em terras minaçuenses o único tipo encontrado é o crisotila. 
de produção e uso "seguros" e "controlados" (Amaral, 2019).

\section{Passos rumo ao ocultamento das DARs: a construção simbólica de uma family ideology entre a SAMA e a população de Minaçu}

Além das melhores remunerações salariais de Minaçu, a empresa mineradora SAMA disponibilizava toda uma série de benefícios aos funcionários que envolve: assistência social; atendimentos médico, odontológico e hospitalar; plano de previdência privada complementar; educação infantil, básica e profissionalizante; atividades socioambientais, festivas e de lazer. Ademais, no que tange ao conjunto da comunidade minaçuense, foi através, principalmente, dos milhões de reais gerados pelo pagamento de impostos como o ICMS (Imposto sobre a Circulação de Mercadorias e Serviços) e a CFEM (Compensação Financeira da Exploração de Recursos Minerais ou royalties ${ }^{7}$, mas também dos inúmeros investimentos diretos à administração local, que a prefeitura de Minaçu conseguiu garantir o funcionamento do único hospital público da cidade, o pagamento dos salários de servidores municipais e comissionados, a oferta de serviços essenciais de urbanização e o constante patrocínio a eventos culturais, religiosos e esportivos, que também movimentavam a economia e o turismo naquele município.

Essa série de benefícios diretos e indiretos propiciou a vinculação afetiva da população à empresa mineradora SAMA, e não apenas por conta da oferta de milhares de contratos de trabalho formal ao longo dos mais de 50 anos de funcionamento em território goiano. Várias pessoas com as quais mantive contato em Minaçu defendiam, às vezes com muito fervor, a continuidade da exploração do amianto crisotila e do beneficiamento industrial de suas fibras por aquela mineradora. Afinal, elas disseram, a empresa deu "sustento" e "amparo" a muitas gerações de famílias locais. Não é à toa, portanto, que a mineradora seja pensada localmente como "a mãe de Minaçu”, por representar ideias como enraizamento, estabilidade, proteção, solidez e permanência (Guedes, 2011), além de ter autoridade socioeconômica e institucional reconhecida e legitimada pela população minaçuense. Foi a SAMA que "segurou as pontas" nos momentos de crise financeira e habitacional vividos por centenas de famílias que encontraram sua morada definitiva em Minaçu, impedindo assim que elas deixassem o município para migrarem repetidas vezes em busca de melhores condições de vida.

Esta simbologia reporta, também, ao fato de a fundação/consolidação daquele município (a partir do ano 1967) estar umbilicalmente ligada à história dessa empresa no Estado de Goiás, a qual detém o monopólio da exploração do crisotila no Brasil, sendo uma subsidiária do maior grupo nacional produtor de materiais de fibrocimento à base de amianto: a Eternit do Brasil Cimento Amianto S.A ${ }^{8}$.

Ao mesmo tempo, a "mãe de Minaçu" é dura, severa e autoritária (cf. Guedes, 2011). Um exemplo, que ilustra bem essas últimas características, pode ser tomado da vez em que representantes da Associação Brasileira dos Expostos ao Amianto (ABREA) foram àquela cidade para dar apoio a um grupo de moradores revoltados com a SAMA, na tentativa de fundar ali a Associação Goiana dos Expostos ao Amianto (AGEA). Antes mesmo da chegada daqueles representantes, vindos do
7 Fontes: Instituto Mauro Borges de Estatísticas e Estudos Socioeconômicos (IMB), e Departamento Nacional de Produção Mineral/Desempenho do Setor Mineral GO e DF: 20082016, respectivamente.
8 Em 29 de novembro de 2017, o Plenário do Supremo Tribunal Federal (STF) declarou a inconstitucionalidade do artigo $2^{\circ}$ da Lei Federal $n^{\circ} 9.055 / 95$, que regulamenta a extração, industrialização, comercialização e o transporte do asbesto crisotila e dos produtos que 
Estado de São Paulo a Minaçu, rumores corriam a cidade alardeando uma suposta ameaça feita pelo presidente do Sindicato dos funcionários da mineradora. Este, por sua vez, é identificado pelos revoltados como “o sindicato da SAMA”, por sempre ter atendido aos interesses políticos e econômicos da empresa, além de contribuir ativamente na construção social tanto de uma vigilância sobre os (ex-) funcionários da empresa mineradora - que estabelece uma espécie de "etiqueta [moral] que regula o que pode ou não pode ser dito, permeado por relações de poder" (Víctora; Sarti, 2004, p. 10) - quanto de um silêncio coletivo a respeito dos inúmeros casos de trabalhadores grave e fatalmente adoecidos a partir da exposição ocupacional às fibras do crisotila na área industrial da SAMA.

De acordo com um de meus interlocutores de Minaçu, ouvia-se no boca a boca que "se a Fernanda [Giannasi, uma das principais lideranças públicas na luta pelo banimento do amianto no Brasil] botasse o pé na cidade, ele [o presidente do Sindicato] iria dar um tiro na cara dela”. Pois Fernanda e os demais integrantes da ABREA afirmavam que "Minaçu tá respirando amianto"9 e que os moradores de lá, inclusive aqueles que nunca trabalharam na SAMA, estavam todos contaminados pelo pó do crisotila. Estes fatos ocorreram no ano de 2006. Em resposta a um e-mail encaminhado a Giannasi antes de eu realizar o trabalho de campo em Minaçu (a partir de setembro de 2016), solicitando informações sobre possíveis contatos da AGEA, ela então escreveu que esta associação nunca se consolidou naquele município goiano, pois a empresa mineradora havia cooptado a diretoria da AGEA, bem como assediado e ameaçado de morte suas principais lideranças.

\section{Abordando um assunto constrangedor}

É de se esperar, portanto, que os vínculos “maternos" e "maternais" estabelecidos pela mineradora, com parcela significativa dos minaçuenses, me trouxeram certas dificuldades durante a realização do trabalho de campo em Minaçu. Sobretudo em relação ao falar sobre os casos de adoecimento e morte de antigos funcionários da SAMA, decorrentes da inalação/ingestão das fibras de amianto. Não chega a ser um tema-tabu, mas tocar nesse assunto específico levantou diferentes suspeitas por parte dos moradores em relação à minha presença naquela cidade - apesar de, em todas as circunstâncias e previamente, me identificar como um pesquisador do doutorado em Antropologia Social da Universidade Federal de Goiás (UFG), vindo da capital Goiânia, e de destacar os objetivos de minha pesquisa em Minaçu. Recorrentes foram as recusas de alguns interlocutores em concederem entrevistas gravadas a mim, de maneira a limitarem suas participações a poucos minutos de conversas informais e pontuais. Nestes momentos, era explícita a tentativa de se distanciarem de qualquer possibilidade de acusação contra a SAMA. Apresento, a seguir, um exemplo concreto de uma abordagem que causou embaraços entre mim e a interlocutora.

Remeto aqui ao meu encontro com Arlete ${ }^{10}$ em novembro de 2016. Antes de conhecê-la pessoalmente, entrei em contato com o processo de adoecimento de seu pai, Júlio, relatado no Dossiê Amianto Brasil (2010). A partir de entrevista com a sua viúva Nair, dos laudos médicos de exames realizados por Júlio e de sua certi- o contenham no Brasil. Em outras palavras, a Suprema Corte proibiu a continuidade da mineração, do beneficiamento industrial, da comercialização, do transporte e da distribuição do amianto crisotila, bem como dos produtos de fibrocimento-amianto, em todo o território nacional. Até a publicação do acórdão dessa decisão em fevereiro de 2019, a SAMA havia mantido suas atividades produtivas em Minaçu. Quatro meses depois, em 16 de julho de 2019, a Assembleia Legislativa de Goiás aprovou, em dois turnos, a Lei 20.514, que autoriza, para fins exclusivos de exportação, a extração e o beneficiamento do amianto da variedade crisotila no Estado de Goiás. Esta lei estadual foi imediatamente sancionada pelo atual governador de Goiás, Ronaldo Caiado.

9 Entrevista, 22/10/2016, Minaçu.

10 Todos os meus interlocutores de Minaçu foram identificados através de nomes fictícios. 
dão de óbito, ficamos sabendo que esse antigo funcionário da SAMA trabalhou na mineradora no período entre julho de 1974 e agosto de 1998, tendo falecido aos 49 anos de idade por conta de insuficiência respiratória aguda e de um câncer no pulmão. Porém, estranhamente as conclusões indicadas naqueles laudos foram todas unânimes: "Ausência de alterações pleuropulmonares por exposição ao asbesto".

Em seu depoimento aos deputados federais que produziram o Dossiê, Nair contou que Júlio trabalhava em um dos laboratórios da empresa, mas que ia constantemente às cavas da mina de Cana Brava para recolher amostras de rochas contendo as fibras do crisotila. Durante seis meses, Júlio apresentou tosse e insuficiência respiratória constante e progressiva, extremo cansaço ao caminhar a curtas distâncias, além de sangramento nasal. Com o prolongamento destes sintomas, ele então procurou o médico do setor de Saúde Ocupacional da SAMA, que inicialmente lhe receitou apenas um xarope para a tosse. Devido às frequentes crises de falta de ar em seu marido, Nair solicitou ao médico um balão de oxigênio - pedido que foi prontamente negado por ele (Dossiê Amianto Brasil, 2010).

Dada a persistência e o agravamento dos sintomas, o médico da mineradora solicitou outro exame para Júlio, que deveria ser analisado por um oncologista de Goiânia (GO). Em dezembro de 2005, o seu nódulo pulmonar maligno foi, finalmente, detectado com a seguinte ressalva: muito provavelmente, o câncer já estava presente no corpo de Júlio há quase cinco anos (em 2000, portanto), embora os exames feitos anteriormente "nada" detectassem. Somente após esse diagnóstico é que o seu adoecimento asbesto-relacionado fora reconhecido pela Junta Médica contratada pela SAMA. A partir disso, a empresa mineradora passou a custear o tratamento quimioterápico de Júlio na capital goiana. Todavia, em fevereiro de 2006, exatamente dois meses após o início da quimioterapia, o senhor Júlio veio a óbito.

Com estas informações em mente, fui atrás de dona Nair no endereço residencial indicado na certidão de óbito de seu esposo. O documento havia sido publicado no Dossiê Amianto Brasil (2010). Após duas tentativas frustradas, sem encontrar qualquer pessoa no local, resolvi perguntar a um vizinho de Nair se ela ainda morava na mesma casa. Acabei descobrindo que o vizinho era, na realidade, genro daquela senhora. Porém, para a minha surpresa, ele me contou que Nair já havia falecido há cerca de dois anos (portanto, em 2014). Agora, apenas uma de suas filhas, Arlete, residia no imóvel. O genro ainda revelou que a sua esposa, irmã de Arlete, era funcionária da SAMA e que sua cunhada teria lhe mostrado, poucos dias antes, fotos antigas de Júlio vestido com o uniforme alaranjado da SAMA e coberto, "dos pés à cabeça", pelo pó branco do amianto crisotila. Uma semana depois, voltei novamente ao local e encontrei Arlete limpando a varanda de sua residência.

Identifiquei-me a ela contando, brevemente, sobre a pesquisa em Minaçu e que eu tinha uma noção dos fatos que antecederam a morte de seu pai. Arlete me olhou com desconfiança, demonstrando não ter tempo para entrevistas, pois, sendo professora em tempo integral, ela teria apenas os finais de semana para realizar as tarefas domésticas. Apesar disso, pude ainda conversar com Arlete por 
quase vinte minutos antes de ir embora. Ela confirmou algumas das informações que constam no Dossiê, mas fez questão de ressaltar (em duas oportunidades) que Júlio morreu porque fumava quase dois maços de cigarro por dia, e não devido à inalação das fibras do crisotila presentes no ambiente de trabalho. Quando soube que seu cunhado havia contado sobre as fotos de Júlio, nas quais ele aparece coberto pelo pó branco daquele mineral, Arlete fechou a cara imediatamente, como que contrariada com a indiscrição do parente. Mesmo se sentindo pouco à vontade com a minha presença, ela ainda contou duas histórias com a intenção de me fazer desistir da procura por documentos que revelassem as causas do adoecimento de Júlio.

Num primeiro momento, Arlete informou que a casa onde morava havia sido invadida e que os ladrões furtaram, entre outras coisas, todas as suas fotos. Posteriormente, alegou que, dias antes de nosso encontro, ela mesma teria jogado fora os exames e relatórios médicos de seu pai, pois já não precisava mais deles. Apesar de não responsabilizar a SAMA pela morte de Júlio, insistindo sempre em reafirmar o seu hábito de fumar diariamente vários cigarros "Marlboro", Arlete reconheceu enfim que seu pai "recebeu do sindicato um dinheiro que ele tinha direito" no valor de $\mathrm{R} \$ 30$ mil.

Este valor se refere a uma indenização paga pela empresa mineradora apenas aos ex-funcionários cujas DARs foram diagnosticadas, oficialmente, pelos pneumologistas que compõem a Junta Médica a serviço da SAMA. Durante os dez meses em que residi no município de Minaçu, eu conheci alguns daqueles trabalhadores. Nestes casos, também pode ser oferecido um plano de assistência médico-hospitalar, gratuito e vitalício, custeado pela SAMA. É preciso destacar que a constante negativa desses interlocutores - os quais são, em sua grande maioria, pobres ou de classe média baixa - a uma discussão mais aprofundada sobre o adoecimento de funcionários da mineradora, após longos ou curtos períodos de trabalho com o amianto, revelou os intensos e eficazes vínculos de dependência em relação aos "benefícios" oferecidos pela empresa.

Sem o plano de saúde, tais pessoas jamais poderiam pagar por uma assistência médica que lhes permite realizar, com frequência e sem custos adicionais às suas escassas poupanças, os exames solicitados pela SAMA, além de um check-up completo para o acompanhamento de sua saúde debilitada. Incluem-se aqui exames de próstata e de sangue, consultas a oftalmologistas e cardiologistas, entre outros serviços médicos cuja procura pessoal é mais recorrente. Já o recebimento de uma indenização por estar "com o peito cheio de pó” (de amianto) - expressão utilizada, constantemente, por alguns de meus interlocutores em Minaçu - poderá representar um ganho financeiro inesperado, mas extremamente necessário para o pagamento do aluguel residencial e de outras contas acumuladas e atrasadas, dos materiais para a construção da casa própria, e/ou dos muitos e caros remédios receitados no curso de seus tratamentos.

No caso particular de Arlete, associar a morte de seu pai à inalação/ingestão das fibras do crisotila poderia gerar retaliações (ameaças e assédio moral) por parte da SAMA, de maneira a colocar em risco a permanência de sua irmã como 
funcionária da mineradora e, consequentemente, a continuidade do recebimento daqueles variados benefícios descritos no primeiro parágrafo do item anterior.

Por outro lado, tornaram-se interlocutores-chave de minha pesquisa etnográfica, em Minaçu (GO), as viúvas e os filhos de antigos funcionários da SAMA que faleceram após vários anos de trabalho com o amianto crisotila, cujos sinais e sintomas médicos das doenças que os levaram à morte nunca foram identificados como expressões clínicas de DARs. Esses trabalhadores, como também os familiares de seus círculos de afeto, depararam com a ausência completa de qualquer tipo de medidas reparatórias oferecidas pela empresa mineradora, ao longo de seus duradouros processos de adoecimento. São eles, cujas dores e sofrimentos jamais foram reconhecidos publicamente, que estiveram/estão revoltados com a indiferença e o desamparo propositais por parte dos representantes da SAMA. Daí se sentirem menos ameaçados por ela, mostrando-se mais dispostos a verbalizar (no âmbito doméstico apenas) duras críticas em relação à "mãe de Minaçu”.

Foi através de seus detalhados depoimentos e de toda a documentação que guardam até hoje (relacionada ao trabalho de seus maridos/pais na mineradora, a seus relatórios e laudos médicos, além de certidões de óbito), que pude conhecer toda uma política de negação e encobrimento das doenças asbesto-relacionadas, promovida por determinados médicos pneumologistas de universidades públicas brasileiras, mas também vinculados profissionalmente aos interesses econômicos do grupo SAMA/Eternit.

\section{O conluio entre a indústria do amianto e médicos/pesquisadores no Brasil}

Em junho de 1997 foi iniciada a execução do projeto de pesquisa epidemiológica e interinstitucional: Morbidade e Mortalidade entre Trabalhadores Expostos ao Asbesto na Atividade de Mineração, no periodo de 1940 a 1996 (cf. Projeto Asbesto-Mineração, 2000). A pesquisa foi coordenada por três pneumologistas e docentes de faculdades de Medicina de universidades públicas paulistas: Ericson Bagatin (coordenador-geral/UNICAMP), Mário Terra Filho (INCOR/USP) e Luiz Eduardo Nery (Escola Paulista de Medicina/UNIFESP).

O objetivo central do estudo epidemiológico era identificar as taxas de eventuais agravos à saúde, associados à contaminação pelo amianto crisotila, entre 4.653 (ex-) funcionários da SAMA no Estado da Bahia ${ }^{11}$ e/ou em Minaçu (GO). Na população da amostra estavam trabalhadores que estiveram expostos às fibras do crisotila durante suas atividades laborais em minas e usinas da SAMA, no período entre os anos 1940 e 1996 (Projeto Asbesto-Mineração, 2000). Considerando o relatório final apresentado pelos pesquisadores em dezembro de 2000, destacam-se as seguintes conclusões (IBC, s/d):

$\checkmark$ Em relação à mortalidade, houve apenas dois casos de câncer em ex-funcionários que eram tabagistas frequentes e acentuados, mas que não tinham asbestose associada à doença.

$\checkmark$ “Após 1977, quando começou a ser implantado o controle de exposição [às
11 Fundada em 1939, a SAMA iniciou suas atividades em 1940 na antiga mina de São Félix, que está localizada no então município de Poções (atual Bom Jesus da Serra), Bahia. Durante seus 27 anos de operação ininterrupta, quase 26 mil toneladas de amianto crisotila foram extraídas da mina até o seu exaurimento total em 1967. Devido a isso, a mineradora transferiu todo o seu maquinário e boa parte de sua mão de obra para a região da mina de Cana Brava, no Estado de Goiás. 
fibras do asbesto crisotila] na Mina [de Cana Brava], 99,5\% dos 1.400 trabalhadores examinados apresentaram ausência de alterações pleuropulmonares” (p. 2).

$\checkmark$ A morbidade decorrente do agravamento de alguma doença asbesto-relacionada, na população total considerada pelo estudo, é de apenas 2,5\%.

$\checkmark$ A baixíssima frequência de alterações pleuropulmonares entre os antigos trabalhadores da mina de Cana Brava, a partir da década de 1980 (quando o controle da exposição ocupacional às poeiras de amianto começou a ser mais rigoroso e a automatização de certas etapas do processo produtivo na SAMA começou a ser efetiva), reflete a menor toxicidade do crisotila, desde que utilizado em condições seguras e controladas.

Por outro lado, de acordo com as informações obtidas pelos então deputados federais da Comissão de Meio Ambiente e Desenvolvimento Sustentável, da Câmara Federal, que produziram o Dossiê Amianto Brasil (2010), na fase de avaliação do projeto de pesquisa mencionado acima, o seu coordenador geral havia garantido aos Comitês de Ética em Pesquisa daquelas três universidades paulistas, mais aos CEPs do CNPq e da Fundação de Amparo à Pesquisa do Estado de São Paulo, que o estudo epidemiológico contaria em sua integralidade apenas com o financiamento da FAPESP. Todavia, segundo os relatores do Dossiê, o estudo contou com, aproximadamente, $48 \%$ de recursos públicos e $52 \%$ de recursos privados e vinculados à indústria do amianto no Brasil.

Trabalho anterior revela que mais de 3,5 mil acordos extrajudiciais foram celebrados entre o grupo SAMA/Eternit e os seus ex-funcionários diagnosticados com doenças asbesto-relacionadas (cf. Barbosa, 2013). Tais acordos são firmados na tentativa de as empresas do amianto, no Brasil, impedirem que os trabalhadores recorram à justiça comum contra elas. Desse modo, o grupo SAMA/Eternit consegue manter em sigilo a quantidade oficial total de adoecidos pela exposição ocupacional às fibras do crisotila, já que com os acordos esse número fica indisponível ao Sistema Único de Saúde (SUS), ao (então) Ministério do Trabalho e Emprego, e à Previdência Social. Como são realizados os acordos extrajudiciais?

De maneira geral, os trabalhadores com asbestose, placas pleurais, câncer de pulmão e/ou mesotelioma, entre outras DARs, são avaliados por uma Junta Médica composta pelos mesmos profissionais que coordenaram e executaram o projeto de pesquisa discutido logo acima: os pneumologistas Ericson Bagatin, Mário Terra Filho e Luiz Eduardo Nery. Esta Junta é contratada pelo grupo SAMA/Eternit através de uma empresa privada que os três médicos mantêm em sociedade. São eles os responsáveis pela avaliação clínica de um conjunto de exames como radiografia do tórax, tomografia computadorizada e testes de função respiratória dos funcionários da mineradora. Tais exames são realizados periodicamente pelos trabalhadores do amianto, a pedido do médico do setor de Saúde Ocupacional da SAMA, por meio de profissionais da saúde e de clínicas particulares já pré-definidos pela empresa, nas cidades de Goiânia e/ou de São Paulo. Os gastos com transporte, 
alimentação e hospedagem desses "colaboradores" ${ }^{12}$ (e de seus acompanhantes, dependendo de cada caso) naqueles dois municípios são todos custeados pela SAMA. Eles também não pagam nada pelos exames, pois o seu custeamento é dever da mineradora e está previsto no Anexo 12 da Norma Regulamentadora $n^{\circ}$ 15 (NR-15) da CLT, de 1 de maio de 1991.

Uma vez realizados esses exames e constatada a presença de DARs, a Junta identifica a gravidade da incapacitação respiratória do paciente - desconsiderando, assim, a existência de DARs em diferentes órgãos que não pertencem ao sistema respiratório. Caso o trabalhador adoecido concorde em abrir mão de seus direitos de impetrar qualquer tipo de ação judicial por reparação de danos físicos e/ ou morais contra a SAMA, a empresa mineradora lhe oferece um plano de saúde gratuito para auxiliar o acompanhamento de seu quadro clínico e arcar financeiramente com o tratamento médico correspondente. Também pode ser oferecida uma indenização em dinheiro, cujo valor varia de acordo com o estágio de sua doença pulmonar.

Diante destas considerações, é perceptível a conveniência dos resultados a que chegaram os pesquisadores do Projeto Asbesto-Mineração (2000) em relação aos interesses da SAMA. O alegado "ínfimo" índice de morbidade e mortalidade entre os trabalhadores expostos às fibras do crisotila, na mina de Cana Brava e nas usinas da SAMA em Minaçu, vem referendar e dar embasamento "científico" às decisões da Junta Médica ao emitir, em diversos casos de trabalhadores com DARs, laudos com a seguinte conclusão-padrão: Ausência de alterações pleuropulmonares por exposiç̧ão ao asbesto.

Durante a realização do trabalho de campo em Minaçu, deparei com três casos que exemplificam muito bem tal situação. Nestes, os trabalhadores adoecidos faleceram após longas experiências de dor e sofrimento familiar provocadas pelo surgimento de diferentes sinais e sintomas de doenças asbesto-relacionadas. Suas viúvas e seus filhos os descreviam detalhadamente: falta de ar progressiva; tosse constante e acentuada; fortes dores no tórax, nas costas e no abdome; cansaço extenuante, que os impedia de caminhar em curtas distâncias e de executar atividades manuais simples; emagrecimento; hemorragia interna, eliminação de sangue pela boca e coloração verde-amarelada (de pele e olhos) em decorrência de tumores malignos no fígado; irritação e insônia por conta de insuficiência respiratória grave. Nenhum desses antigos funcionários da SAMA teve o seu adoecimento reconhecido, oficialmente, pela Junta Médica da mineradora.

Os estudos antropológicos que trabalham e discutem o conceito de sofrimento social mostram-nos uma complexa inter-relação entre i) múltiplas formas de percepção dos riscos à saúde, em diferentes contextos socioculturais e históricos, e ii) certas questões referentes a processos político, econômico, institucional, moral e/ou legal capazes de infligir danos devastadores à experiência humana - conferir, entre outros, os variados textos organizados na inspiradora coletânea Social Suffering (Kleinman; Das; Lock, 1997). Problemas individuais e coletivos são então analisados inseparavelmente, de maneira a revelar todo um conjunto de níveis interpessoais de sofrimento. Além disso, a possibilidade do reconhecimento da
12 Maneira como a SAMA identifica todos os seus funcionários. 
dor dos outros é percebida como sendo factível somente se essa experiência for capaz de ser traduzida e comunicada. A dor humana passa então a ser um evento da linguagem e, portanto, um processo cultural (cf. Le Breton, 2013; DelVecchio Good et al., 1992; Helman, 2003; Sarti, 2001).

No próximo item, apresento um dos relatos que ilustram muito bem as experiências de sofrimento social de que tomei conhecimento a partir da pesquisa etnográfica em Minaçu. Tais experiências são ainda vividas por aqueles familiares cujo pai, ou marido, veio a óbito após inúmeras passagens por clínicas e hospitais (públicos ou privados) de Minaçu e, sobretudo, de Goiânia, sem nunca terem suas doenças associadas à exposição ocupacional ao asbesto crisotila na SAMA.

\section{"Eu entrei em desespero! Pra mim, o chão abriu e eu afundei"}

Augusto nasceu em 1944 na zona rural da cidade goiana de Carmo do Rio Verde, embora tenha conhecido e se casado com Sandra - a interlocutora que me narrou a história de seu marido - no município de Goianésia (GO). Desempregado e sobrevivendo através do plantio de alimentos e da criação de poucos animais como galinhas e porcos, ele decidiu abandonar sua pequena lavoura e se mudar com a esposa, e quatro filhos pequenos, para a cidade de Minaçu. A ideia surgiu depois que um tio seu, que já trabalhava na mineradora SAMA e acompanhava a situação precária em que o sobrinho e sua família viviam na roça, o convidou para se juntar a ele, pois, na época, a empresa estava contratando dezenas de outros trabalhadores. Em outubro de 1978, Augusto, Sandra e os filhos se mudaram definitivamente para Minaçu. Mas foi somente um ano depois que ele conseguiu um emprego formal na mineradora.

Atuando inicialmente na função de servente de pedreiro, auxiliando a construção de diferentes obras civis no interior da área industrial da SAMA, poucos anos depois Augusto passou a trabalhar com a extração do amianto crisotila no interior das cavas da mina de Cana Brava. Nesta nova função, ele operava uma máquina conhecida como perfuratriz, que é utilizada no desmonte da rocha amiantífera. Eram os tempos (décadas de 1970, 80 e 90) em que a gigantesca demanda comercial pelas fibras do crisotila, nos mercados brasileiro e internacional, obrigava a SAMA a operar 24 horas por dia e sete dias por semana. Augusto trabalhou na mineradora durante quase 15 anos seguidos, entre 1979 e 1994.

Três anos após ser dispensado da empresa, Augusto começou a sentir dores nas costas e na região do tórax, além de apresentar tosse, falta de ar e um cansaço físico que se agravaram gradualmente. Porém, os resultados tanto de seus exames clínicos de rotina, realizados por médicos da empresa enquanto ele ainda era um "colaborador", quanto daqueles (raios-X, espirometria e tomografia computadorizada) feitos a cada ano pelos ex-funcionários em clínicas particulares da capital Goiânia, "não indicavam" a presença de DARs em seu corpo. Com o passar dos anos, a insuficiência respiratória e as dores se intensificaram a tal ponto que as recorrentes internações de emergência no Hospital Municipal de Minaçu (via SUS), ou na Policlínica 24h (particular), passaram a fazer parte da rotina de Augusto. Nestes dois estabelecimentos, ele recebia um tratamento médico à base de 
analgésicos, de medicação para "abrir" os brônquios, e de altas doses de oxigênio.

O laudo da primeira tomografia de tórax que Augusto realizou, numa clínica particular de Goiânia, indicou uma anormalidade em seu pulmão direito. Porém, de acordo com o documento, não era possível apontar um diagnóstico exato apenas com aquele exame. Poucos dias depois de retornar a Minaçu, Augusto teve uma crise respiratória e por isto foi encaminhado ao Hospital Municipal, onde ficou internado. Ao examinar sua tomografia, o médico que atendeu Augusto naquela ocasião comentou com Sandra e seus filhos: "Olha, o seu [Augusto] tem um problema. É bom vocês levarem ele a Goiânia [para] fazer mais exames”.

Acatando a sugestão do médico, Sandra e Augusto voltaram à capital goiana para que ele fosse consultado por um pneumologista. Vale destacar que esta consulta foi paga com recursos financeiros de Augusto, em uma clínica desvinculada a priori da mineradora SAMA. Portanto, não é possível afirmar que o especialista e a clínica onde atendia foram indicados pelo próprio médico do hospital público de Minaçu ${ }^{13}$. O que se sabe é que depois de conversar com Augusto, analisar a sua tomografia e ler o relatório sobre o exame, o pneumologista lhes garantiu: "[Ele] está bem. Não tem problema nenhum, não tem nada”. Como Sandra ainda insistia em reforçar os sintomas de falta de ar e tosse constantes do marido, o pneumologista decidiu então receitar a ele um simples xarope e uma medicação para os brônquios, que devia ser inalada, via oral, através de uma bombinha - fato este que deixou Sandra bastante indignada.

Frustrados com a ausência de um diagnóstico médico para os seus sintomas e de um tratamento efetivo, Augusto e Sandra retornaram outra vez a Minaçu. Suas crises respiratórias se intensificavam, com o passar do tempo, e com elas as internações de Augusto no Hospital Municipal ou na Policlínica 24h se tornaram recorrentes. Sandra se recorda que durante as crises, sobretudo à noite, seu esposo ficava bastante inquieto sem conseguir dormir. Há tempos já não permanecia deitado na cama, pois esta posição agravava ainda mais a sua falta de ar.

Além das dores nas costas e no peito, Augusto passou a ficar preocupado com uma dor, até então desconhecida, que começou a sentir na região abdominal. Com o agravamento tanto da insuficiência respiratória quanto das dores no abdome, um dos médicos que atendiam Augusto no Hospital Municipal decidiu encaminhá-lo, através do Sistema Único de Saúde, ao Hospital Estadual de Urgências de Goiânia (HUGO). Lá Augusto poderia fazer exames mais precisos que identificassem a origem daquele novo sintoma. Uma equipe médica do HUGO descobriu então o seu "problema de vesícula", que apenas seria solucionado com a remoção cirúrgica do órgão. "Eu já não sabia qual problema agravava ele mais, né. Se era a vesícula ou se era esse problema de falta de ar", relatou Sandra. Como é de praxe, o médico que iria operar Augusto solicitou que ele realizasse alguns exames pré-operatórios para averiguar se estava, de fato, apto para a cirurgia. Foi a partir daí que a suspeita de câncer pulmonar apareceu pela primeira vez, fazendo com que o médico solicitasse então uma biópsia do pulmão direito de Augusto.

O SUS autorizaria a biópsia somente quinze dias após o encaminhamento do pedido. Mas o exame devia ser feito com urgência, advertiu o médico - Augusto
13 Os médicos que trabalham no Hospital Municipal atuam, também, no Hospital "da SAMA" (como é identificado localmente) e/ou na Policlínica 24h - inclusive o médico responsável pela área de Saúde do Trabalho da mineradora. Em novembro de 2001, a SAMA e a Cooperativa local dos Trabalhadores da Saúde (COOP Saúde) assinaram um acordo de comodato para a prestação de serviços médicos e odontológicos à população de Minaçu. 
não poderia esperar quase duas semanas para realizá-lo. Daí podermos deduzir que o seu problema pulmonar já se encontrava em estágio bastante avançado, embora nenhum outro médico o tivesse revelado anteriormente. Sensibilizado com o fato de Sandra não ter, naquela ocasião, o dinheiro suficiente para pagar por uma biópsia, o médico do HUGO resolveu então ligar para um patologista, amigo seu, e perguntá-lo se este poderia fazer o exame gratuitamente. A biópsia foi, enfim, realizada no mesmo dia. Mas o seu resultado abalou o paciente e sua família: “[...] descobriram que ele tava com um câncer [maligno] no pulmão [direito]".

Apesar das fortes dores na região da vesícula, o médico não pôde operá-lo porque a cirurgia no pulmão exigia prioridade máxima. Foi então que Augusto fora encaminhado ao Hospital Araújo Jorge (HAJ) - ou Hospital do Câncer, como é conhecido não apenas em Goiás, mas também por seus pacientes vindos de outros Estados brasileiros. Chegando lá, outro médico alertou Sandra que a remoção do pulmão direito de Augusto consistia num procedimento de alto risco, pois ele poderia morrer durante a cirurgia ou em decorrência de uma forte pneumonia no período pós-operatório. O profissional também avisou que caso Augusto não fosse operado, ele poderia vir a óbito a qualquer momento, mesmo se fizesse um tratamento quimioterápico. Por outro lado, ele tinha chances de sobreviver à cirurgia. Se isto de fato ocorresse, Augusto teria "99\% de chances de cura", lembrou-se Sandra. Apesar deste dilema, passados dois dias de muita reflexão, Augusto acabou optando pela cirurgia.

Enquanto ele estava internado numa enfermaria do HAJ, se recuperando de uma cirurgia tão incisiva, Sandra solicitou ao médico que cuidava de seu marido um laudo atestando a incapacidade permanente de Augusto para o exercício de qualquer tipo de atividade laboral. A expectativa era que, através deste documento, ele se aposentasse por invalidez ou conseguisse, pelo menos, receber o auxílio-doença junto à Previdência Social. Sem conseguir trabalhar e, portanto, sem ter uma fonte de renda, Sandra e seu marido sobreviviam graças a uma pequena poupança acumulada ao longo de décadas e à ajuda financeira de seus filhos. Embora os dois não pagassem aluguel, parte significativa da receita familiar era gasta nas compras de caros medicamentos e de balões de oxigênio para Augusto, além do custeio com transporte, alimentação e outras despesas emergenciais.

Daí a preocupação de Sandra em pedir ao médico de Augusto que ele fizesse "um laudo bem arrumadinho", de maneira que a perícia do Instituto Nacional do Seguro Social não contestasse a condição de invalidez permanente do ex-funcionário da SAMA. Porém, o documento que recebeu atestava a presença de duas doenças crônicas pulmonares: o enfisema e a neoplasia (câncer) maligna associados a tabagismo "de longa data". Relacionar o adoecimento de Augusto exclusivamente ao fato de ter sido, durante décadas, um fumante ativo não era uma novidade para ele. Afinal, todos os médicos que o atenderam, após o surgimento dos sintomas de tosse, falta de ar e cansaço, perguntavam se Augusto fumava cigarros, com qual frequência e durante quanto tempo, sem levar em consideração todos os quinze anos em que trabalhou como operador de perfuratriz na mina de Cana Brava, em Minaçu, onde ficava completamente exposto às fibras do amianto crisotila. 
Sandra contestou aquele laudo, pois o documento não indicava a presença de asbestose nos pulmões de Augusto, apesar de a sua fisioterapeuta e uma médica integrantes da equipe de profissionais da saúde que cuidaram dele no período em que ficou internado no Hospital do Câncer - terem afirmado confidencialmente a Sandra que, pelos sintomas clínicos apresentados pelo marido, havia uma grande possibilidade de Augusto ter mesmo aquela doença asbesto-relacionada.

Abro parênteses apenas para destacar que, desde fevereiro de 2013, a SAMA é considerada uma "Empresa Amiga do Hospital Araújo Jorge" e como "Empresa Parceira no combate ao câncer". Isto se deve ao fato de a mineradora de amianto ter doado 24 poltronas para pacientes em tratamento quimioterápico, além de já ter contribuído mensalmente com o custeio e a manutenção daquela instituição de saúde (cf. Amaral, 2019). Esta parceria ocorreu oito anos após a internação e a cirurgia de Augusto no HAJ (em 2005). Não é possível concluir, portanto, que o apoio firmado entre a SAMA e o HAJ também ocorreu em anos anteriores. Mas não deixa de ser, no mínimo, estranha e suspeita a intensa colaboração da SAMA com um hospital que recebe/recebeu vários ex-funcionários da mineradora adoecidos após vários anos de alta exposição às fibras do crisotila.

Ao longo dos meses que se passaram após a cirurgia, Augusto ia apresentando uma boa recuperação, embora ainda necessitasse inalar doses de oxigênio praticamente 24 horas por dia. Contudo, as dores na região abdominal se intensificaram, mostrando que o problema na vesícula ainda era permanente. Nesta época (em 2006), as idas de Augusto a hospitais de Goiânia e Minaçu continuaram a fazer parte de sua rotina, seja para monitorar a evolução de seu quadro de saúde pós-operatório ou, então, para receber medicação analgésica voltada ao alívio das dores abdominais. Em uma de suas internações no Hospital Municipal de Minaçu, um médico da instituição solicitou que Augusto fosse encaminhado (novamente pelo SUS) ao Hospital São Salvador, na capital, para que ele pudesse ser consultado por um gastroenterologista.

Uma vez em Goiânia, esse especialista decidiu então que a cirurgia de remoção da vesícula era o procedimento mais adequado ao caso de Augusto. Enquanto fazia a cirurgia, o médico verificou uma anormalidade ainda mais grave no fígado, que somente seria diagnosticada por meio de uma biópsia. Outra vez Augusto e Sandra foram pegos de surpresa. Os temores em relação à existência de mais um câncer rondavam a sua família. Passados poucos dias, o resultado daquele exame finalmente chegou às mãos do gastroenterologista, trazendo notícias bastante desanimadoras: havia mesmo a presença de um tumor maligno no fígado do ex-funcionário da SAMA.

No período em que Augusto realizou o tratamento quimioterápico, durante os oito meses que antecederam à sua morte, Sandra contou que ela e o marido viviam muito mais em Goiânia, com o apoio de uma cunhada, do que em Minaçu. As sessões de quimioterapia, a fraqueza corporal, a falta de apetite e as dores intensas e constantes seguidas de hemorragia interna, que fazia Augusto vomitar sangue, o obrigavam a ficar recorrentemente internado no HAJ. O amargor da bílis em sua boca, além da coloração verde-amarelada tanto da pele quanto dos olhos, eram 
sinais de que o tumor no fígado já estava em estágio avançado. Como os efeitos colaterais da medicação quimioterápica eram muito fortes e as dores, hemorragias internas e crises respiratórias continuavam (pois agora só possuía um pulmão), Augusto não podia mais se ausentar de Goiânia.

Todavia, estando extremamente fragilizado, Augusto não suportava mais aquela agonia interminável.

Sandra: A doutora me chamou e falou: "O seu [Augusto] não tem jeito mais. Ele não vai resistir mais do que 72 horas. A senhora pode levar ele pra casa". Aí eu entrei em desespero! Pra mim o chão abriu e eu afundei, sabe? [...]. Eu queria porque queria trazer ele [para Minaçu]. Aí eu falei: "Doutora, nós vamos levar ele. Os meninos [seus filhos] tão aqui de carro próprio". Ela: "Não, de carro próprio não pode. Tem que ser de ambulância".

Aí ele entrou em coma. Eu conversando com ele assim, de boa, aí eu vi quando ele parou assim... Ele só me olhava. Os olhos dele se enchiam d'água. Aí eu entrei em desespero! Eu balançava ele. Eu conversava com ele. Aí ele já não me respondia nada mais. Aí eu saí correndo, chamei a médica. Ela foi [e disse:] "Agora não tem jeito mais, não".

$[\ldots]$

Aí os meninos chegaram e a ambulância chegou também. [...] Nós colocamos ele dentro da ambulância e trouxe pra cá. Na hora que tava chegando em Minaçu, ele faleceu. Ele faleceu dentro da ambulância.

Autor: $\mathrm{E}$ nesse caminho de Goiânia a Minaçu, como é que tava o seu [Augusto]?

Sandra: Parecia que ele tava dormindo. De olho fechado. Aí ele entrou em coma [outra vez]. A gente olhava pra ele e pensava que tava dormindo. $\mathrm{Na}$ hora que ele morreu... ele fez vômito e abriu o olho um pouquinho. Aí, pra mim, ele tava melhorando. Falei: “Filha, seu pai tá melhorando!". Eu gritei numa altura tão grande! Falei: “Graças a Deus seu pai tá melhorando!”. Mas como ela é técnica de enfermagem, ela reconhece, né. Ela: "Mãe, meu pai não tá melhorando. Meu pai tá acabando...". E foi verdade. Aí a gente já tava chegando em Minaçu e veio direto pro hospital [municipal]. Nós chegamos duas horas da manhã aqui em Minaçu com ele. Foi triste demais... Aí foi o fim dele. Dia 16 de outubro de 2007 ele faleceu (Entrevista, 14/01/2017, Minaçu-GO). 
A certidão de óbito de Augusto foi atestada por um dos médicos que trabalham no Hospital Municipal de Minaçu e, também, no Hospital "da SAMA". Nela consta que as causas da morte daquele ex-funcionário da mineradora foram: "falência múltipla de órgãos, câncer de pulmão e doença oncológica metastática”. Contudo, não havia no documento qualquer menção da possível associação daquela causa mortis com a exposição ocupacional pregressa às fibras do crisotila. A ausência completa de um diagnóstico que identificasse as doenças letais de antigos trabalhadores do amianto, em Minaçu, como DARs, também foi constatada em outras certidões de óbito a que tive acesso direto por meio do consentimento informado e (por razões ético-metodológicas já explicitadas na introdução deste artigo) informal de alguns de meus interlocutores locais.

\section{Considerações finais}

A estruturação narrativa deste artigo foi proposta de maneira a exibir uma espécie de iceberg simbólico. Sua parte imersa é composta por todos os fatores sociais, econômicos, morais (através da construção de uma family ideology por parte da SAMA: a "mãe de Minaçu”), médico-científicos e institucionais que possibilitaram a ocorrência das doenças asbesto-relacionadas no município goiano de Minaçu. Já a sua parte visível é constituída pelo sofrimento social corporificado (cf. Víctora, 2011) nos trabalhadores adoecidos de maneira fatal pelas fibras do amianto crisotila e que, ainda em vida, estavam revoltados por conta do ocultamento e, mesmo, da negação de suas DARs.

Ao afirmar que o sofrimento social é a parte visível dessa estrutura metafórica, ressalto que, no contexto minaçuense, ele somente foi assim compreendido na perspectiva de minha pesquisa etnográfica. Isso porque as aflições e todo o mal-estar físico resultantes do agravamento das condições de saúde daqueles antigos funcionários da mineradora SAMA, bem como a angústia dos familiares de seus círculos de afeto e intimidade, jamais foram publicamente reconhecidos pela população de Minaçu, por profissionais de saúde e nem por instituições médico-hospitalares, jurídicas ou de assistência social nos âmbitos federal, estadual e municipal.

Sem o devido reconhecimento legal dessas pessoas como vítimas, de fato, do amianto, restou à dona Sandra - mas também às viúvas de outros ex-"colaboradores" da empresa mineradora SAMA, as quais eu tive a oportunidade de conhecer em Minaçu - expressar verbalmente a compreensão e, ao mesmo tempo, o ápice das trajetórias de sofrimento e desespero diante da inevitabilidade da morte dolorosa e solitária de seu marido Augusto: "Para mim, o chão abriu e eu afundei". 


\section{Referências}

AMARAL, Arthur Pires. Com o peito cheio de pó: uma etnografia sobre a negação do adoecimento de trabalhadores do amianto na cidade de Minaçu (GO). 2019. Tese (Doutorado em Antropologia Social) - Universidade Federal de Goiás, Goiânia, 2019.

BARBOSA, Fábio de Macedo T. Imperialismo e produção do espaço urbano: a indústria do amianto e a construção da cidade de Minaçu-GO. Tese (Doutorado em Geografia) Universidade de São Paulo, São Paulo, 2013.

CONFORTI, Paul M.; KANAREK, Marty S.; JACKSON, Lorene A.; COOPER, Robert C.; MUR$\mathrm{CHIO}$, Jack C. Asbestos in drinking water and cancer in the San Francisco bay area. Journal of Chronicals Disease, v. 34, p. 211-224, 1981.

DELVECCHIO GOOD, Mary-Jo; BRODWIN, Paul E.; GOOD, Byron J.; KLEINMAN, Arthur. 1992. Pain as human experience: an anthropological perspective. Berkeley; Los Angeles; London: University of California Press, 1992.

DOSSIÊ AMIANTO BRASIL. Relatório do Grupo de Trabalho da Comissão de Meio Ambiente e Desenvolvimento Sustentável da Câmara dos Deputados destinado à análise das implicações do uso do amianto no Brasil. Brasília-DF, 2010.

DUARTE, Luiz F. Dias. Ética de pesquisa e "correção política” em antropologia. In: VícTORA, Ceres; OLIVEN, Ruben G.; MACIEL, Maria Eunice; ORO, Ari P. (Orgs.). Antropologia e Ética: o debate atual no Brasil. Niterói: EdUFF-ABA, 2004. p. 125-130.

GUEDES, André Dumans. O Trecho, As Mães e Os Papéis: movimentos e durações no norte de Goiás. Tese (Doutorado em Antropologia Social) - Universidade Federal do Rio de Janeiro/ Museu Nacional, Rio de Janeiro, 2011.

HAMMOND, C. E.; SELIKOFF, Irving J.; SEIDMAN, Herbert. Asbestos exposure, cigarette smoking and death rates. Annals of the New York Academy of Sciences, v. 330, n. 1, p. 473-490, 1979.

HELMAN, Cecil G. Cultura, saúde e doença. 4. ed. Porto Alegre: Artmed, 2003.

IBC - Instituto Brasileiro do Crisotila. s/d. Informações recebidas sobre a única pesquisa do gênero específica para o amianto realizado no Brasil. Goiânia. Disponível em: https://incubadora.ufrn.brindex.phpsequatorialıuserssetLocalespt_BR. Acesso em: 18 maio 2017.

KLEINMAN, Arthur; DAS, Veena; LOCK, Margaret. Social suffering. Berkeley: California University Press, 1997.

LANDRIGAN, Philip J.; NICHOLSON, William J.; SUZUKI, Yasunosuke; LADOU, Joseph. The Hazards of Chrysotile Asbestos: a critical review. Industrial Health, n. 37, p. 271-280, 1999.

LANGDON, Esther Jean; MALUF, Sonia; TORNQUIST, Carmen Susana. Ética e política na pesquisa: os métodos qualitativos e seus resultados. In: Ética nas pesquisas em ciências humanas e sociais na saúde. São Paulo: Hucitec, 2008. p. 128-147.

LE BRETON, David. Antropologia da dor. São Paulo: Fap-Unifesp, 2013. [Edição original: 1995].

MCCULLOCH, Jock. Asbestos Blues: labour, capital, physicians \& the state in South Africa. Oxford; Bloomington; Indianapolis: James Currey \& Indiana University Press, 2002. 
Arthur Pires Amaral

PROJETO ASBESTO-MINERAÇÃO. Relatório final do projeto Morbidade e Mortalidade entre Trabalhadores Expostos ao Asbesto na Atividade de Mineração: 1940-1996. Campinas-SP. 2000. Disponível em: http://www.ibcbrasil.org.br/midias/downloads/ 06-mineracao-cancer-pt.pdf. Acesso em: 19 maio 2017.

SARTI, Cynthia. A dor, o individuo e a cultura. Saúde e Sociedade, v. 10, n. 1, p. 3-13, 2001.

VÍCTORA, Ceres G. Sofrimento social e a corporificação do mundo: contribuições a partir da Antropologia. RECIIS - Revista Eletrônica de Comunicação, Informação e Inovação em Saúde. Rio de Janeiro, v. 5, n. 4, p. 3-13, 2011.

VícTORA, Ceres G.; SARTI, Cynthia. Apresentação. Horizontes Antropológicos, Porto Alegre, ano 20, n. 42, p. 9-18, jul.-dez. 2014.

WALDMAN, Linda. The Politics of Asbestos: understandings of risk, disease and protest. London, Washington-DC: Earthscan, 2011. 